\title{
FUNCTIONAL TEXTILES - FROM RESEARCH AND DEVELOPMENT TO INNOVATIONS AND INDUSTRIAL UPTAKE
}

\author{
Paul Kiekens ${ }^{1}$, Els Van der Burght ${ }^{1}$, Erich Kny², Tamer Uyar ${ }^{3}$, Rimvydas Milašius ${ }^{4 *}$ \\ ${ }^{1}$ Ghent University, Department of Textiles, Belgium, Technologiepark 907, B-9052 Zwijnaarde; \\ ${ }^{2}$ Kemyk, Austria, Angelika Fajtgasse 5, 7000 Eisenstadt; \\ ${ }^{3}$ Bilkent University, UNAM-Institute of Materials Science \& Nanotechnology, Turkey, 06800 Ankara; \\ ${ }^{4}$ Kaunas University of Technology, Department of Materials Engineering, Lithuania, Studentu 56 LT-51424 Kaunas. \\ *e-mail: rimvydas.milasius@ktu.It
}

\begin{abstract}
:
Functional textiles are one of the most important fields in textile industry and textile materials science. They include breathable, heat and cold-resistant materials, ultra-strong fabrics (e.g. as reinforcement for composites), new flameretardant fabrics (e.g. intumescent materials), optimisation of textile fabrics for acoustic properties, etc. Functional textiles became more and more important materials for various applications and interest in them grew year by year; and more and more conferences are focused on functional textiles, as well as the events which are not only textile conferences but encompass various fields of Material Science. This paper presents a short overview about the European Materials Research Society 2014 Fall meeting conference Symposium M "Functional textiles - from research and development to innovations and industrial uptake" and the projects which participated as symposium co-organisers: the European Coordination Action 2BFUNTEX funded by the EC 7th Framework Programme NMP, the COST Action MP1105 on "Sustainable flame retardancy for textiles and related materials based on nanoparticles substituting conventional chemicals (FLARETEX)" and the COST Action MP1206 on "Electrospun Nano-fibres for bio inspired composite materials and innovative industrial applications".
\end{abstract}

\section{Keywords:}

Functional textiles, flame retardancy, electrospinning, FP7 Coordination Action 2BFUNTEX, COST Action MP1105 FLARETEX, COST Action MP1206

\section{Introduction}

The symposium on functional textiles has been organised within the European Materials Research Society (E-MRS) 2014 Fall meeting. E-MRS was founded in 1983 and now has more than 3200 members from all over Europe - from industry, government, universities and research centres who meet regularly to debate recent technological developments of functional materials [1]. More than a few thousands researchers participate in E-MRS Spring and Fall meetings. The Fall meeting is being organised since 2002 and always in Warsaw (Poland) at the time of which several symposia are organised. In 2014, it was the first time, a symposium was focused on functional textiles. E-MRS conferences are the largest events of European researchers in Material Science. More than 1000 researchers attended the E-MRS 2014 Fall meeting conference (where 23 symposia have been organised) in Warsaw from $15^{\text {th }}$ to $18^{\text {th }}$ September, and more than 70 of them participated in Symposium M "Functional textiles - from research and development to innovations and industrial uptake".

The proposal to organise a symposium on functional textiles had been submitted to E-MRS in the beginning of 2013 when the idea to participate in such a huge event arose at the FP7 2BFUNTEX [2] workshop in Eibar (Spain). At the end of 2013, the positive decision from E-MRS was received and for the first time, a symposium focused on textile materials has been organised within an E-MRS meeting. Later, the two COST Actions MP1105 [3] and MP1206 [4] joined the Symposium M as co-organisers. The Symposium $M$ lasted 3 days, from $16^{\text {th }}$ to $18^{\text {th }}$ September 2014 and more than 40 oral and 15 poster presentations were presented. The symposium provided a forum to present and discuss the latest scientific achievements, developments and innovations in the field of functional textiles and presented the possibilities for their industrial applications. The symposium brought together all innovation actors in the field fostering a multidisciplinary approach between universities, research institutes, SMEs (in textiles, 95\% of the companies are SMEs) and sector associations. It helps to identify technological gaps and eliminate barriers, resulting in a faster industrial uptake of added value functional materials with new functionalities and improved performance and resulting in creation of new business worldwide. The symposium also helps to boost the international cooperation in different complementary research areas to allow enhanced development of functional textile structures and textile related materials through collaboration at European level between researchers in different universities, research institutes and industry. The Symposium $M$ has given an overview of the developments of functional textile-based structures of tomorrow. All presentations have been divided into three groups according to the projects - flame retardant textiles, electrospinning and other functional textiles. At the start of the symposium, plenary presentations about each project were presented and the goals as well as the obtained results 
of the projects have been disseminated to all participants. The goal of this paper is to present the projects co-organised at Symposium $M$ and to disseminate the information about them to all readers of the Autex Research Journal that has been selected by E-MRS and the symposium organisers as the main journal for publishing of selected symposium papers.

\section{2BFUNTEX: Transfer of innovations functional textiles towards industry}

2BFUNTEX is a 4-year duration European Coordination Action funded by the EC $7^{\text {th }}$ Framework Programme NMP that was started on $1^{\text {st }}$ January 2012 . The objective is to bring together all innovation actors in the field of functional textile structures and textile related materials, fostering a multidisciplinary approach between universities, research institutes, industry (especially SMEs) and sector associations. The 2BFUNTEX international team aims to identify technological gaps and eliminate barriers resulting in a faster industrial uptake of functional materials with new functionalities and improved performance. Technological needs are being mapped, new joint international research disciplines will be identified and multidisciplinary teams (MDTs) have been created. Training materials for research and industry purposes are being elaborated and implemented, allowing a common language regarding functional textiles and increasing the number of well-trained people in this field. MDTs that collaborate along a specific research topic will play a key role. Through the development of an interactive website with an extensive database, collaboration will be boosted and rapid industrial uptake catalysed and enhanced.

2BFUNTEX aims at developing a platform for current and future actions in research, education and technology transfer in the field of functional textile structures and textile related materials to support the textile industry in the most efficient and effective way to transform into a dynamic, innovative, knowledgedriven competitive and sustainable sector. 2BFUNTEX will be a platform for all actors involved in innovation in European projects, including interested companies not yet active in the field and users. The main objective of 2BFUNTEX is to support research and industrial innovation actors, that is, universities, research institutes along with industry, in their efforts to define joint research projects and actions in the above-mentioned field. MDT teams have been created that are oriented towards tapping the experienced potential related to functional materials, with the aim to enhance transfer of the vast knowledge available at universities and research institutes to industry and to favour rapid industrial uptake.

The overall objectives of 2BFUNTEX comprise:

- collection of all relevant information related to ongoing research and activities in the field of functional textile structures and textile related materials using modern detection methodologies (such as the 2BFUNTEX website);

- detection of synergies and gaps and the creation of project ideas in the field of functional textile structures and textile related materials. The information received will be used to create project ideas to be elaborated in tangible project teams and concrete RTD projects to enable the effective technology transfer to industry;

- development of an interactive database with information on activities on functional materials. This is expected to be a tool box to find information on status of technology, people involved, contacts, possibilities and limitations. In addition, ongoing projects can use the database as a portal for disseminating information and contacting targeted people.

- provision of training and education to increase the number of well-trained people who continue their (research) activities in functional materials related industry and to better train people already employed in industry

- a variety of dissemination activities, such as: development of an interactive website (comprising the aforementioned database); distribution of written materials (brochures, photo book, ...); publication of newsletters; visits to industry; organisation of and participation in conferences, workshops (for SMEs), brokerage events, training courses, ...; participation at fairs and exhibitions.

- creation of MDTs performing research in the field of functional materials and oriented towards industry aiming at the creation of new business worldwide. The final goal of 2BFUNTEX is to consolidate all information gained in solid collaborations between research and industry, resulting in the enhanced identification of new functional materials and rapid translation of research ideas into industrial products.

An Open Innovation Platform on functional textiles was created which is available via the project website www.2BFUNTEX.eu and includes several databases: on projects, on technologies available (including equipment and testing facilities), a list of events and trainings and a training materials database. All researchers (from universities, research institutes and research \& development centres in companies) are invited to register and upload information on their own current and future actions in research, education and technologies available. On the Open Innovation Platform, industry (as well as researchers) can express their needs (e.g. new technologies, products, processes, testing, research partners, ...), which are treated confidentially, in order to connect industry with available technologies or research capacities. For companies, www.2BFUNTEX.eu will also be the place to visit to detect new technologies and business opportunities.

A bibliometric analysis of published literature was performed by the Austrian Institute of Technology (AIT), one of the 2BFUNTEX partners, to get an overview of research in the field of functional textiles (see Figure 1) [5]. Topics were identified with their relation to each other, as well as top organisations, journals, cited references and other relevant information for each topic. In a next step, a thorough investigation and identification of patents clusters in functional textiles and fibres was done. Bibliometric analyses were also performed to map patents. The basic idea was to get an overview of 'hot' patent topics and applications in the domain of "functional textiles". The results are made publicly available on the 2BFUNTEX Open Innovation Platform in the section "Publications".

Based on the training materials \& training needs that were collected, six training topics were identified for the development 


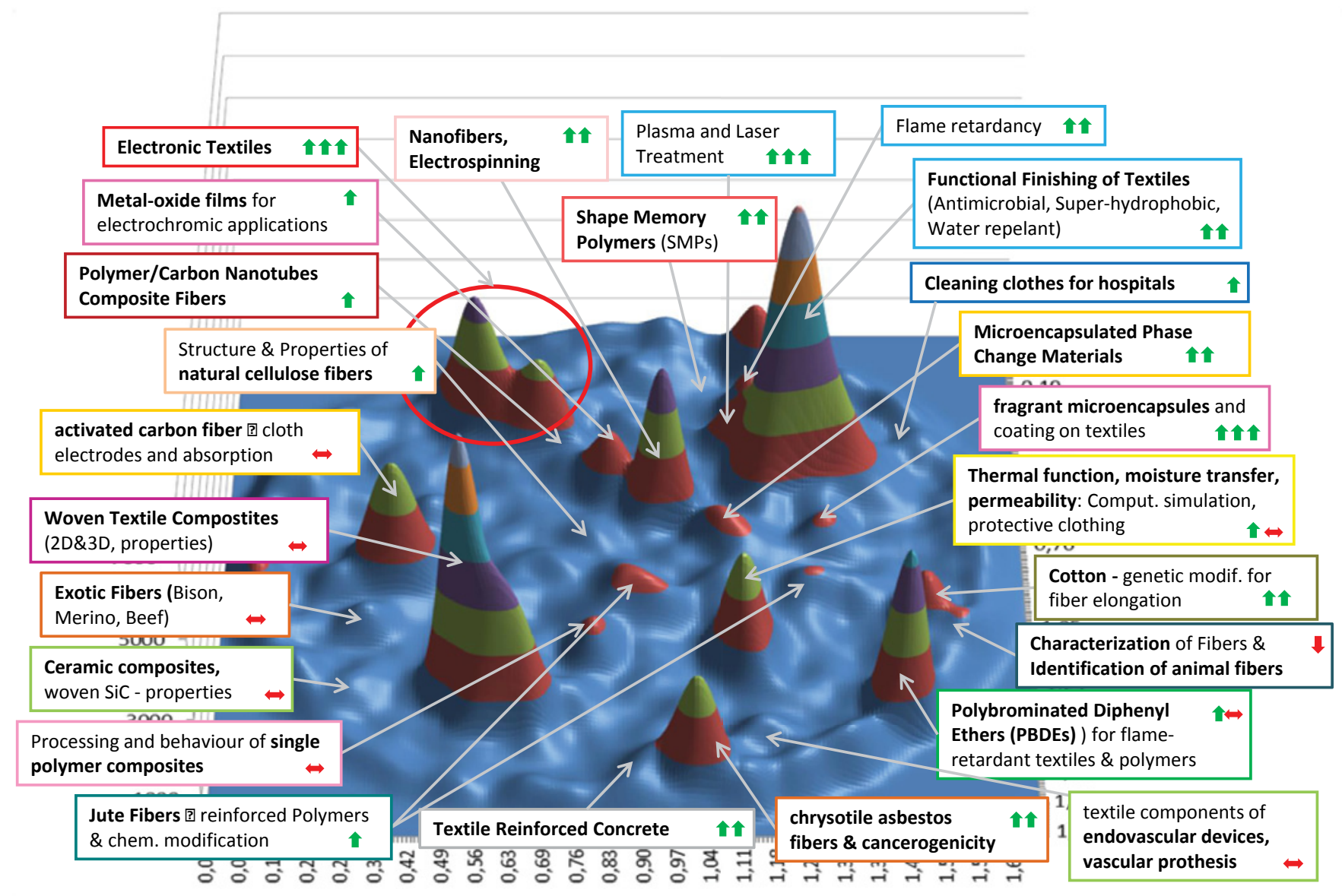

Figure 1. Analysis of Research Fronts in Scientific Publications on "Functional Textiles" 1989-2012. Depicted are 8931 recorded articles. Arrows indicate the dynamic of research activity over the last 10 years: green arrows indicate that a topic is increasing, red arrows that a topic is decreasing or stable. The graph was drawn up by AIT using BibTechMon ${ }^{\mathrm{TM}}[5]$.

of course modules, namely: smart textiles, nanotechnologies, electrospinning, sustainable materials, textile recycling and protective functional textiles.

Several scientific conferences were organised by the 2BFUNTEX partners to disseminate information on functional textile innovations. For example the "International Istanbul Textile Congress 2013 on Innovative and Functional Textiles" in Istanbul, Turkey, at the end of May 2013 with approximately 300 participants from all over the world was very successful. This conference was followed by a brokerage event and technoshow organised with the help of the European Enterprise Network (EEN). On 23 ${ }^{\text {rd }}$ October 2013, 2BFUNTEX and EEN organised, with the support of the EUREKA project E!Surf, an innovation seminar annex matchmaking event on functional textiles (2BFUNTEX@eurofinish2013) with crossover from and towards the coating and surface treatment sector in the framework of the Eurofinish Exhibition in Ghent (Belgium). There were over 60 participants from 17 different countries. During the innovation seminar, 10 companies and research organisations presented their innovation or project ideas, and in the afternoon, 121 faceto-face meetings took place. On Tuesday $1^{\text {st }}$ April 2014, a full session within the $9^{\text {th }}$ Annual ETP Conference of the European Technology Platform for the Future of Textiles and Clothing (with 148 participants) was dedicated to the 2BFUNTEX project, its technology transfer support tools and how they can be used by the industry. Further, a 2-day 2BFUNTEX Session on functional textiles was organised within IITAS 2014, the XIII International Izmir Textile and Apparel Symposium from $2^{\text {nd }}$ to $5^{\text {th }}$ April in Antalya, Turkey. During the symposium, recent innovations and sector-specific issues of the textile industry and textile related sub-sectors were discussed together with the exchange of information. More than 600 participants (academic, executives and employers working in textile and apparel industries and students) from 19 countries attended this symposium. Furthermore, five 2BFUNTEX newsletters were published and widely disseminated across Europe towards main textile stakeholders, as well as published on the 2BFUNTEX website.

Based on the analysis of the technology-innovation gaps, eight MDTs that collaborate on the following specific research topics were identified and set up: antimicrobial textiles, smart textiles, nanotechnologies, flame retardancy, biotechnologies, electrospinning, plasma and sustainable textiles. Each MDT is led by a research and an industrial team leader and will identify some tangible gaps between available technologies and medium- to long-term industrial needs. All MDTs are also open to researchers and industrial persons from outside the 2BFUNTEX consortium.

The final aim of the project is to assist the process of creating new project ideas and establishing MDTs that can be addressed for research purposes and possible industrial applications in the years to come. Bringing together all actors in the field, that 
is fostering a multidisciplinary approach between universities, research institutes, SMEs and sector associations, and identifying technological gaps as well as eliminating practical barriers will result in a faster industrial uptake of innovative functional textile structures and textile related materials. SMEs will be involved in the MDTs to allow researchers to better orient their joint efforts towards industrial applications. Additionally, the SMEs will be able to adapt their methods of production, management and distribution at an early stage. Thus, it is expected that 2BFUNTEX will boost the coordination of research and the uptake of new products and processes by industry.

The 2BFUNTEX consortium includes 26 partners from 16 European countries. They represent a balanced mix between nationality (of great importance for the collection of information on national/regional projects, dissemination to local industry), technical expertise, market expertise, size (large enterprise and SME but also small research groups and large groups) and type (research institute, university, industry, SME). The full list of 2BFUNTEX partners is available on the 2BFUNTEX website. Further, an industrial advisory Board (IAB) has been set up to validate the strategy and progress of the project and give information on the industrial needs in the field of functional textiles and textile related materials. This IAB includes both large companies and SMEs at different levels in the value chain and a representative of EURATEX, the European Apparel and Textile Confederation.

\section{COST Action MP1105: sustainable flame retardancy for textiles and related materials based on nanoparticles substituting conventional chemicals (FLARETEX)}

Replacement of existing flame retardants (FR) with sustainable and environmentally friendly alternatives for textiles in domestic, safety, transport (automotive, rail, aerospace and marine), civil emergency and military, construction and other industries requires a multidisciplinary approach from textile technology to the physics and chemistry of fire. Therefore, the COST Action MP1105 FLARETEX was started that aims to create an international multidisciplinary scientific and technology network on sustainable flame retardancy, developing new innovative FR with low fire toxicity, environmental impacts and free of halogen. In particular, this platform will help to promote cooperation in flame retardancy research between researchers from different scientific disciplines, efficiently exchanging ideas and strategies in order to lead developments in fire safety, fire retardants and environmentally friendly fire-retardant textiles and related materials, and accelerate growth to keep Europe leading the world in this crucial area, taking into account sustainability, safety and health, and to facilitate its commercial exploitation in Europe. COST MP1105 stimulates European cooperation and technology transfer to industry with valuable input from (inter)nationally funded research via working group meetings, workshops, conferences, training schools and short-term scientific missions (STSM) for early stage researchers (ESR), etc.

The main aim of the COST Action FLARETEX is to form a European multidisciplinary knowledge platform on sustainable flame retardancy to facilitate the rapid development of fire-safe textiles and related materials of low toxicity and ecotoxicity, using all the available and novel technologies. To reach this goal the following objectives are set:

- To identify and bring together various research activities occurring in this area in different academic and industrial sectors and different scientific disciplines (such as chemistry, physics, materials science and engineering).

- To address aspects related to technical, environmental, economic, medical and societal issues relating to the use of FRs.

- To organise activities to allow the coordination of research on a European level, avoiding duplication of efforts and linking industry and (academic) research.

- To facilitate the commercialisation of the novel research products/processes developed by academics through SMEs as well as influence the main European industrial flame retardant textile interest.

- To facilitate the formation of consortia to develop new research projects for funding from national/EU funding bodies.

- To establish a fully functional network where each participant is aware of the activities, expertise and previous experience of other members working in their area.

- To establish a repository of published research on fireretardant textiles (to include books, journal articles, conference proceedings, patents, ...).

- To promote placements and exchanges of scientific personnel across the network.

- This COST Action will generate and coordinate research activities aimed at:

- Identification of the safer alternative to halogenated and antimony-based FRs.

- Development of new and sustainable nanobased FR systems for application in textile and related materials.

- Analysis of their effectiveness, durability, (smoke) toxicity and particularly environmental impact (LCA).

- Improved surface treatment (plasma, enzymes, ultrasound, UV, etc.) and application processes (coating, spinning, sol-gel, micro-encapsulation, (photo) chemical, etc.) for FRs.

- Drawing up of testing methods, performance standards and durability requirements for FRs in different sectors (protective clothing, automotive, construction, packaging, etc.).

- Study of the synergistic effect of combining nanomaterials with conventional FRs.

- Development of a modelling tool, based on the existing knowledge of FRs and new scientific results, to be used by industry to predict the properties of newly designed products in an optimal way.

- Characterisation, safety aspects, quality assurance, property database.

- Scaling up and commercialisation.

In order to be able to coordinate the work in the above research fields, the COST Action MP1105 is organised into four working groups (WG):

WG1: Novel FR: New and environment friendly (halogenfree) nanobased flame retardant systems are investigated 
and/or developed. Synergistic effects derived from combining nanoparticles with conventional FRs and their potential effectiveness are studied. Molecular modelling of thermal degradation will be applied in order to get new insights into the mechanisms by which new FRs affect the flammability of textile (based and related) materials.

WG2: Toxicological/environmental aspects: FRs obtained in WG1 are being investigated for their fire toxicity, ecotoxicological and environmental impacts (LCA). The risks and benefits of using FR in consumer products will be analysed both qualitatively and quantitatively. In general, the appropriate human exposure and environmental life cycle risks will be assessed.

WG3: Processing/applications/commercialisation: Application processes (such as plasma coating, spinning, sol-gel, (photo) chemical, ...) of the novel FRs to textiles or textile related materials are being studied, developed and optimised. The general aim is to minimise the amount of novel FRs but still assuring the best fire-retardant performance of the treated materials. Work in WG3 will facilitate the mechanism to commercialise the best products/processes through intensive cooperation with the industrial partners.

WG4: Testing/standardisation: According to the requirements needed for the different application (sub)sectors, new test methods and performance standards can be developed. Durability tests for the novel FR will be standardised as well. Flammability tests might be superseded by fundamental smallscale test methods for making material property measurements that can be used as input to validated end-use computer models.

The following highlights in scientific output have been reported so far:

- The use of nanoparticles for flame retardancy, including natural and hybrid nanoparticles: for example, nanoclays or ceramic particles deposited on the surfaces of glass-reinforced composites can act as effective thermal barriers.

- Increased use of P-based FRs as alternative for halogenbased FRs: for example, the development of an UV-based process for the immobilisation of new non-halogenated flameretardant polyphosphazenes.

- Improvements in flame retardancy of cotton and polyesters by using casein or hydrophobin coatings. Both these proteins, rich in phosphorus $(P)$ and sulphur, favour the formation of coherent char that limits the production of flammable volatile species.

- The use of natural (= green) FR: Deoxyribonucleic acid from herring sperm can be used as an efficient green intumescent ingredient in various polymers.

- The use of layer-by-layer deposition and sol-gel technology: for example, development of new multifunctional precursors exhibiting nitrogen and $\mathrm{P}$ groups - used for the preparation of flame-retardant sol-gel finishings.

- Intumescent FRs as alternative for halogen-based FRs: Rigid PU foam from renewable resources was protected with thermally expandable intumescent mineral fibre mats with expandable graphite that produces a passive fire barrier.

- Novel bicomponent fibres with nanoclay and/or a P flame retardant introduced into the core or sheath of fibre were produced. The fibres with clay and FRs in the sheath showed better FR and mechanical properties than other fibres.

- The use of multifunctional (nano)chemicals combining flame retardancy with other properties (e.g. water/oil repellency, breathability, antimicrobial, ...): e.g. modified PET fabrics exhibit excellent antimicrobial and antistatic properties.

- Improved surface treatment (UV, spray-drying microencapsulation, (atmospheric) plasma pre-treatment, ...): e.g. functionalisation of oxide colloidal nanoparticles by spraydrying micro-encapsulation processes and atmospheric plasma to activate natural fibre composites' surfaces prior to applying a 'sol gel' technique to flame retard them.

- Development of instrumental and computational tools for the investigation of polymer nanocomposite flammability.

The COST Action MP1105 was started in May 2012 and will run until May 2016. At present, it comprises 27 signatory COST countries and 2 non-COST members. During the first 2 years, 15 events were organised: a kick-off meeting, two management committee meetings, one steering group meeting, one cohesive meeting of all WGs, one WG4 standardisation meeting, two industrial workshops, four workshops within large conferences (one jointly with COST Action MP1206), two scientific workshops and one training school. In total, 583 individual participants from various fields representing 42 countries were involved in these events, including 209 from industry. Especially the joint FLARETEX-RSC Conference on FR Technologies (FRT14) included a large industrial participation. All workshops had a very high scientific level and attracted a large number of participants, including many ESRs. Thirteen STSM were concluded, establishing new collaborations between member institutes, providing synergies on a multidisciplinary basis and advanced knowledge to the participating ESRs.

In the $3^{\text {rd }}$ action year the following activities will be organised:

- 16/09/2014-18/09/2014, Warsaw, PL: E-MRS Fall 2014 Symposium M: „Functional textiles- from research and development to innovations and industrial uptake" in cooperation with COST MP1206 and the FP7 Coordination Action 2BFUNTEX.

- 7/10/2014, Dubrovnik, HR: Scientific workshop "Characterisation of flame retardant textile and related materials", linked to ITC\&DC 2014 conference.

-20/10/2014-24/10/2014, Bolton, UK: Training School on "Fire testing according to European/International Standards".

- 2710/2015-29/01/2015, Tampere, FI: Joint COST MP1105 WG1 meeting/2BFUNTEX MDT meeting on Flame Retardancy. -04/02/2015-06/02/2015, Madrid, ES: Workshop on "Advances in Flame Retardancy of Polymeric Materials" within AESP7 conference (https://aesp7.org/fire-retardant-workshop/).

- 26/03/2015-27/03/2015, Bucharest, RO: Workshop on "Advances in the synthesis and characterisation of nanomaterials for flame retardant applications".

-28/04/2015, Montpellier, FR: $4^{\text {th }}$ COST MP1105 MC meeting. - 29/04/2015-30/04/2015, Montpellier, FR: Workshop on "Thermophysical properties, Thermal stability and Fire Retardancy of blends and filled polymers" within EUROFILLERS 2015 conference (http://eurofillerspolymerblends2015.mines-ales.fr/). 
The COST Action MP1105 is always open for new members and covers costs for the networking activities, e.g. workshops, conferences, training schools and STSMs. The research itself is carried out by the participating laboratories, funded through other sources. For more information on how to join, please consult the FLARETEX website http://www.flaretex.eu or contact COST.MP1105@UGent.be.

\section{COST Action MP1206: electrospun nanofibres for bio-inspired composite materials and innovative industrial applications}

Electrospinning, an electro-hydrodynamic process has lately become an exciting and versatile platform technology for the production of nanofibre materials. The electrospinning process takes place between a spinning head with a capillary opening or a rotating drum and a collector counter electrode where a high voltage is applied (typical 10-60 kV) (Figure 2). The spinning head (nozzle or nozzle-less) is connected with and (usually) pressure fed by a reservoir of a polymer solution. The high voltage applied draws at very high speed a nano- to micronsized fibre jet out of the Taylor cone, which forms at the opening of the nozzle. The solvent is rapidly evaporating in this process and the endless nanofibres are collected and deposited at the collector. The electrospun nanofibres are deposited either in an irregular and chaotic fashion to form a nonwoven web or as organised (e.g. parallelised) fibre patches. The uniqueness of electrospun nanofibres is due to their high surface to volume ratio, high fibre interconnectivity and nano scale interstitial space, compared to conventional fibrous structures. As a result, they are of high interest in a diverse range of applications where highly porous structures or structures with a high surface area are desirable, making them potentially very useful for a range of innovative biomedical and technical applications. Biomedical applications include biomimetic scaffolds for tissue engineering, sustained/controlled drug release systems, regenerative medicine, wound dressings, implants, artificial skin and biosensors. Other emerging applications of electrospun nanofibres are in the field of textiles and of filtration for air and liquids and personal respiratory systems for protection from biological and chemical agents. Electrospun nanofibres have been established to be very good candidates for the development of advanced sensors for environmental and biomedical applications (e.g. ultra-sensitive gas sensors, electronic noses, halochromic sensors, flexible reversible lowcost pH-sensors, biosensors, biomolecules microchip array). Indeed such a technique would be compatible and match well with common microelectronic processes and is promising to be a non-expensive technique. Electrospun nanofibres play an important role in the food area, which includes separation operations, enzyme immobilisation, encapsulation of food bioactive compounds and microorganisms, and the fabrication of sensor devices, and in food packaging applications to make them active and intelligent. Other emerging uses are for energy applications (batteries, fuel cells, photovoltaic), catalyst applications and for various electronic and optoelectronic uses. This topic is therefore very important and timely and presents numerous opportunities to contribute towards solving the pressing global challenges in health, water, food, environment and energy issues. The electrospinning technique, as a base tool for novel product development, has gained outstanding relevance in many different research and technical fields.

Thus a COST-networking Action was considered to be very appropriate to create great benefit out of these many potential synergies. That makes this COST-networking Action MP1206 an ideal forum to bring all researchers from the different application areas together to exchange and merge the different approaches of the electrospinning field. Other national or international funding programs with a more focused area cannot create these high synergistic effects among that many different approaches and application fields. It is also crucial to strengthen all the scattered research know-how on electrospun nanofibres all over Europe as to make Europe more competitive on this high value domain.

Electrospinning is at the borderline between pure basic research and industrial implementations in many fields. When looking at the urgent need of European industry (particularly the polymer processing, biomaterials, and the textile and advanced technical systems such as energy, sensors, food packaging and filtering systems) for higher competitiveness, it is of outstanding importance to lead researchers towards

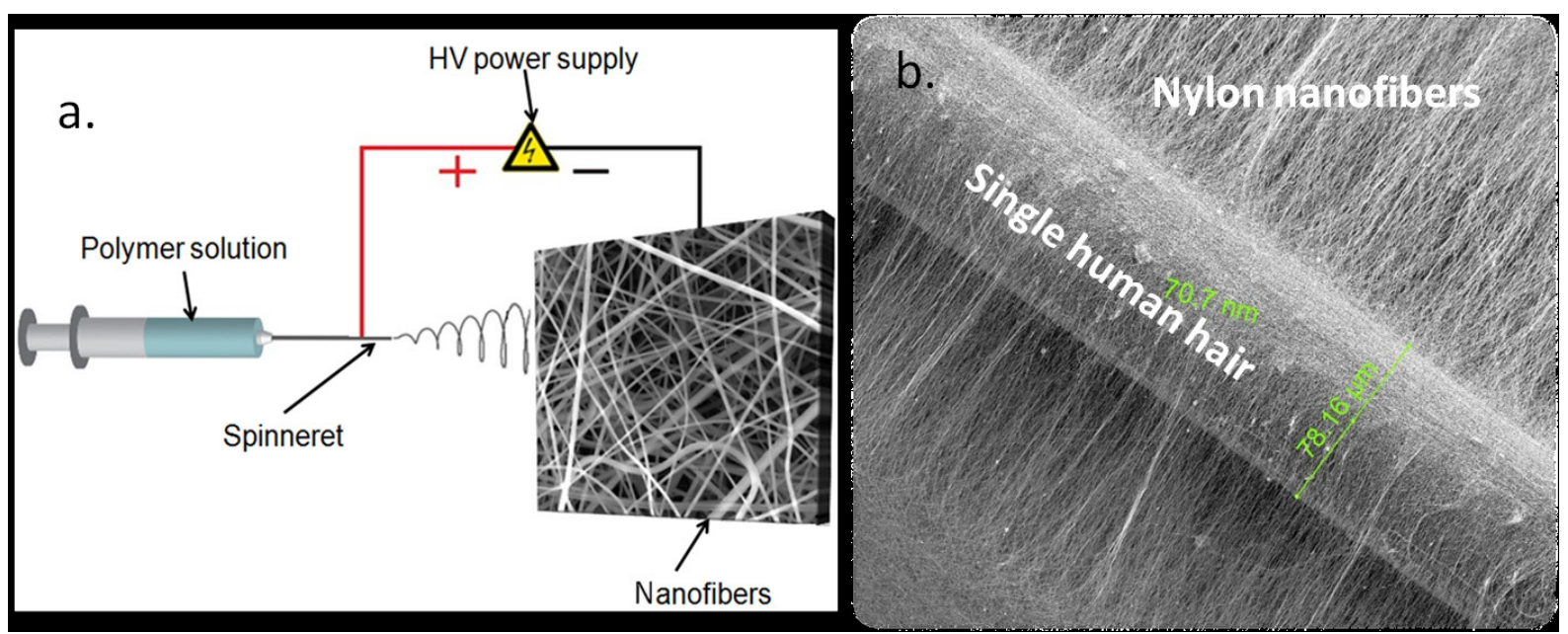

Figure 2. a) Schematic view of electrospinning setup, b) electrospun nylon nanofibers $(\sim 70$ nm in diameter) collected on a single human hair ( 78 micron in diameter) 
the hot spots of research in terms of process and materials improvement and innovative applications. In that way, research institutions as well as European industry are profiting from a highly interconnected COST-networking Action and an improved knowledge base within the field of electrospinning.

By forming an interdisciplinary knowledge platform, the COST Action MP1206 on electrospinning will strengthen the European R\&TD on electrospun nanofibrous materials and nanofibrous composites and will generate fast progress in the state-of-theart. The COST Action will cover scientific breakthroughs and innovations in the electrospinning process itself, nanofibrous materials and nanofibrous composite advancements and the post treatment processing of electrospun materials. Applications in the biomedical and technical fields as well as health, societal and environmental issues are considered.

The COST networking Action MP1206 on electrospinning is also very advantageous and beneficial for young researchers, to obtain a basic overview and improved ideas in the field of electrospinning and the resulting materials applications. By meeting the objectives of the COST Action MP1206 an important step towards the creation of an innovative, knowledge-based and competitive European industry will be accomplished. Moreover, the characteristic high added-value of electrospun nanofibre-based materials means that the related industry would require highly qualified personnel to run the corresponding facilities, with the creation of new professional skills for working within interdisciplinary teams. The COST Action will aim for maximal productive outcome by providing:

- New integrated experimental theoretical methodologies for designing and producing electrospun nanofibres

- Databases of application-relevant electrospun nanofibres properties

- An improved and enlarged knowledge base by scientific articles on electrospun nanofibres

- Tutorial material for training young and more experienced researchers entering the field.

The COST Action MP1206 is organised into five WG :

WG 1: Innovations in the electrospinning process of nanofibres WG 2: New developments and innovations in new electrospun nanofibrous materials technologies

WG 3: Biomedical applications of electrospun nanofibres

WG 4: Technical applications of electrospun nanofibres

WG 5: Health/environment aspects of electrospun nanofibres The COST Action MP1206 was started in May 2013 and will run till May 2017. WG meetings, workshops, conferences, training schools and STSM for ESR (so far, 10 STSM took place), etc. are being organised. Summary of international workshop and training school activities under COST Action MP1206 so far:

- Training school on „Safe and efficient formulations for Electrospinning (SAEFE)", Bayreuth, Germany, 18 September 2013.

- ESR training school, Barcelona, Spain, 4-7 November 2013 (in cooperation with POLYMAR 2013 conference).

- Management committee and workgroup meeting, London, United Kingdom, 3-4 December 2013.

- International workshop on "Electrospun nanofibers in tissue engineering applications”, Antalya, Turkey, 4-5 March 2014.
- First International Workshop on „Electrospinning for High Performance Sensing (EHPS)”, Rome, Italy, 29-30 April 2014. - Training school on "Characterization of Electrospun Nanofibers: Hands-on Experience", Ankara, Turkey, 11-13 June 2014.

- International workshop on „Electrospinning for advanced nanocomposite production”, Aveiro Portugal, 4 July 2014 (in cooperation with ANM2014, Advanced Nanomaterials Conference)

- Training School: Exploiting Electrohydro-dynamics and Rheology for the Control of Nanofibre Structural and Physical Properties, (in cooperation with CISM training school), Udine, Italy, 1-5 September 2014.

- E-MRS Fall 2014 Symposium M: „Functional textiles- from research and development to innovations and industrial uptake" Warsaw, Poland, 16-18 September 2014 (in cooperation with MP1105-FLARETEX and the FP7 Coordination Action 2BFUNTEX).

- International workshop on „Agricultural applications of Electrospinning \& Electrospinning of Agricultural Products", Vienna, Austria, 6-7 October 2014.

The COST Action MP1206 will devote special attention to electrospun nanofibres of major technological interest and will disseminate its outcome to academia, industry and to the general public. In conclusion, the COST networking activity MP1206 within the 36 COST countries will be the ideal instrument to gain strength and speed in these latest and important scientific and industrial developments in the area of electrospun nanofibres. Presently, 32 of the 36 COST countries are participating in this action; in addition, 15 non-COST countries are also participating. Since COST is an open and flexible network, new participants interested in electrospinning will always be welcome, please consult www.electrospinning-cost.eu.

\section{ACKNOWLEDGEMENTS}

The 2BFUNTEX project receives funding from the European Commission within the 7th Framework Programme under the Grant Agreement number 290500 (Theme NMP.2011.2.3-3).

The COST Action MP1105 FLARETEX and COST Action MP1206 received funding from the COST Association that is supported by the EU Framework Programme.

\section{References}

[1] http://www.emrs-strasbourg.com

[2] http://www.2BFUNTEX.eu

[3] http://www.flaretex.eu

[4] http://www.electrospinning-cost.eu/

[5] Wepner B., Wagner, P., Züger, M. (2014): Bibliometric Analysis of Scientific Publications and Patents of Functional Textiles and Fibers. Study conducted within EU-Project "2BFunTex" funded under contract number 290500. p. 11. Accessed at http://www.2bfuntex.eu/sites/default/ files/publication-files/Bibliometric_Analysis_Functional_ Textiles_Overview.pdf on [22.09.2014]. 